\title{
Business model for Smart Hospital health organization
}

\author{
Igor Ilin ${ }^{1}$, Oksana Iliyaschenko ${ }^{1 *}$, and Alexandra Konradi ${ }^{2}$ \\ ${ }^{1}$ Peter the Great St. Petersburg Polytechnic University, Institute of Industrial Management, Economics \\ and Trade, Higher School of Business Management, 195251, Polytechnicheskaya st., 29, Russian \\ Federation \\ ${ }^{2}$ Federal State Budgetary Establishment "National Medical Research Center of V.A. Almazov" of the \\ Ministry of Health of the Russian Federation, 197341, Akkuratova st., 2, Russian Federation
}

\begin{abstract}
Modern trends in the society development such as population growth, increase of longevity, development of medical technologies and trend of business digitalization require adaptation of the services offered by health organizations to the new conditions. The health organizations management shall form a development strategy, and therefore, form and continuously improve the business model taking into account the dynamically changing environment, new technologies, legislation, etc. for successful positioning in the market, saving and developing the value of the services offered in the health care sector. The article provides a reference business model of a health organization based on the Smart Hospital concept. While implementing this concept, the health organization relies on a new computing infrastructure based on mobile and cloud technologies, large data and analytics, Internet of things (IoT), new achievements in machine learning. These revolutionary technologies enable the health organization to drastically change the business models and create new products and services in the health care.
\end{abstract}

\section{Target setting}

The exponential potential growth and increase in capabilities of new technologies in the medicine, the rapid IT development, development and implementation of the ideas of the 4th Industrial Revolution over the past few years have marked the prospect for formation of a completely different health care model.

Let's consider the main current trends in the medicine field. Currently, the "4P" medicine and the value-based medicine concept are most significant. The "4P" medicine concept consists of the following components [1]: preventive medicine, participation medicine, predictive medicine [2, 3], personalized medicine [4]. The value medicine [5] adds the "4P" concept. The medical trends and concepts can be successfully implemented based on the actual digital technologies only. The Health 4.0 is a strategic health care concept based on the Industry 4.0 concept. The Health 4.0 objective is to ensure the implementation of valuebased and personalized medicine ideas through the mass use of actual IT: Internet of Things

\footnotetext{
*Corresponding author: ioy120878@gmail.com
} 
and Internet of Services, capabilities for processing and using a big amount of data (Big Data) [6], cloud computing [7], Machine Learning [8], block chain technology, developed mobile networks $(5 \mathrm{G})$, etc. The use of these technologies makes it possible to create "smart" infrastructure of health organizations, developing the Artificial Intelligence based solutions to provide expert knowledge and analysis of great amount of medical data at a relatively low cost.

The implementation of these concepts and technologies is already transforming the health care sector. In the near future the large-scale introduction of technologies that ensure the implementation of ideas of value-based and personalized medicine will provide an opportunity to implement the Smart Hospital concept. According to the experts in the field of digitalization of health care, the Smart Hospital concept is based on optimized and automated processes supported by the actual IT focused on improving the existing procedures and implementing new opportunities for patient treatment and care [9]. The implementation of the solutions that support the Smart Hospital concept is one of the priorities for large companies offering the relevant IT solutions including SAP, IBM, Siemens, Google, etc., as it is an important component for the business and can help to solve problems regarding reduction of costs in the health care system while maintaining the required health care quality level.

The introduction of such solutions requires the management of health organizations to understand the development strategy and the developed business model. The successful health care business models increase customer loyalty, consumer benefits and can contribute to the creation of a competitive cost structure, taking into account the choice of the appropriate automation option and health organization processes digitization. It is obviously that the business model may have certain characteristics depending on the specific activities of the health organization, environmental conditions, etc. However, regardless of the health organizations specifics, the implementation of the Smart Hospital concept involves the formation of client-oriented business models. They expand the capabilities of drivers, strategies and tools for analyzing, modeling and implementing innovative business models. We offer a service-oriented business model in this article to develop a health organization that is going to implement the Smart Hospital concept.

\section{Methods of research}

To solve the problems, it is necessary to form a health organization business model as mentioned above. We will consider that the business model is an analytical tool for "... description of the basic principles for organization creation, development and successful operation" [10]. The business model is similar to the strategic plan that is later implemented through the organizational structures, processes and systems of the organization.

There are a large number of approaches to the business model formation that have created and evolved in accordance with the needs and changing market conditions: the "closed innovation" business model (Closed R \& D business model) [11], Henry Chesborough's "open innovation" business model [12], D. Debelac's model. [13], A. Osterwalder and Y. Pigneur's approach [10], L. Schwarzer's approach of [14], Chan Kim and Rene Moborn's concept who developed the blue ocean strategy [15], etc.

Having analyzed all the abve approaches to creating the business model, it can be concluded that all the proposed variants of the organization business models are based on 4 key elements that determine its content: a proposal in the form of value for customers that is proposed by the organization based on the produced goods and services; interaction with the consumer, the infrastructure that the enterprise uses to create the value; organization financial efficiency. 
The A. Osterwalder's model advantage is a clear segmentation of all key parameters that reflect the logic of the organization activities and aimed at making a profit. In addition, this model has a tool support, wide practical application and it is used in the activities of a large number of successful concerns and corporations. According to these provisions, we concluded that it is advisable to carry out the research based on the use of A. Osterwalder and Y. Pigneur's business model template. Alexander Osterwalder in cooperation with Yves Pigneur developed a methodology for creating a business model based on the business model template that consists of 9 structural blocks [10]: consumer segments, value proposals, basic activities, key resources, key partners, customer relations, sales channels, revenue streams, and cost structure. Each of the considered blocks has its own description and structure. The practical approach to creating the innovative business models proposed by A. Osterwalder is used in the TOGAF standard of the Open Group industrial consortium, has the Archi tooling, is used in many industries around the world, in particular, by 3M, Ericsson, Capgemini, Deloitte, Telenor, etc.

\section{Research results}

Based on the A. Osterwalder and Y. Pigneur's methodology the following description of the reference Smart Hospital business model is proposed.

Consumer segments. The business model development begins from the definition of consumer segments. In our case, the consumer segments are patients which can be classified according to the different reasons. The patients' classification will be the basis for creating the consumer segments for the health organization. The health organization implementing the Smart Hospital concept renders all types of medical assistance provided by Federal Law No. 323-FZ dd. 21.11.2011 "Basic principles of health care of Citizens of the Russian Federation" (Article 32) [16]. All patients may be classified according to the types of care to be delivered:

- at-risk patients;

- $\quad$ primary care patients;

- $\quad$ specialized and high-tech care patients;

- ambulance and ambulance secondary care patients;

- patients who need postsurgical health monitoring and/or care (including palliative care)

As well as to individuals the health organization can render services to corporate clients. Patients can live directly in the region of the health organization location or be within remote regions including hard-to-reach areas.

The next version of the patients' classification is according to the sources of care funding: CHI (compulsory health insurance), quotas of the Ministry of Health of the Russian Federation, VHI (voluntary health insurance) and direct patient's services payment.

The considered variety of patients in different classifications has some intersections. For example, a corporate client, - a large oil and gas company engaged in the production and processing of petroleum products, has oil derricks within remote, hard-to-reach regions. The company should monitor the health of employees working at remote locations. In this regard, the company is interested in proposals for corporate clients with regard to identifying at- risk and remote health monitoring patients. In this case, the financial interaction is arranged through the VHI.

Another example is arrangement of the postsurgical health monitoring and care. This kind of services should be arranged using the IoT opportunities. For example, the postsurgical health monitoring of apoplectic consists not only in care, but also in rehabilitation course arrangement. The IoT opportunities play an important role in this point. The sensors attached 
to the patient's body allow to obtain information about the patient's condition, the motor activity capabilities, and, if necessary, to promptly adjust the rehabilitation process.

Value-based proposals. The identified consumer segments allow creating a number of value-based proposals supported by appropriate medical and IT in the framework of the Health 4.0 concept:

- $\quad$ services for continuous patients health monitoring;

- $\quad$ services for early diseases detection that is especially important for diseases with high mortality rate [17];

- selection of treatment methods taking into account the patient's genome, life environment features, etc.;

- patients rehabilitation services;

- $\quad$ patients care services (any time and anywhere);

- comprehensive services based on a combination of different value-based proposals. For example, when rendering services for early diseases detection, the patient receives a set of services related to treatment and the need for rehabilitation under special conditions in the framework of the comprehensive proposal;

- $\quad$ services for corporate clients depending on their activities specifics.

Basic activities. All value-based proposals are created in the framework of key activities which the health organization renders in accordance with Federal Law No. 323-FZ dd. 21.11.2011 "Basic principles of health care of Citizens of the Russian Federation" (Article 32) $[16]:$

- $\quad$ medical care (primary, specialized, etc.);

- disease prevention;

- $\quad$ early diseases diagnostics;

- monitoring of patients who received medical care, and at-risk patients;

- implementation of comprehensive medical services from early diseases detection, medical care with subsequent monitoring health condition of at-risk patients or ones who received medical care.

Key resources. Medical concepts and IT are a component of key resources. The main key resources of the health organization implementing the Smart Hospital concept are both the conventional resources, and the resources required for the concept implementation:

1. Material resources - resources that ensure the institution functioning in terms of financial security. The material resources include medical equipment, drugs, buildings and structures, transport resources, utilities (including water and power supply, ventilation systems) and communication channels (telephony, telecommunications, etc.).

2. Staff - human resources providing the health organization activity (doctors, nurses, management personnel, technicians, drivers, IT staff, accountants, personnel department, statistics department).

3. Intellectual resources including scientific developments in the field of biomedicine, genetic engineering, and IT.

4. Information technology resources:

4.1. The Health 4.0 technologies (IoT, Big Data, cloud computation, mobile technologies, machine learning, artificial intelligence, predictive analytics, telemedicine);

4.2. IT solutions of large companies for the medical industry (SAP, IBM, Microsoft);

4.3. "4P" technologies and value-based medicine (VBM).

5. Financial resources assume the definition of all sources of organization activities funding. In case of health organizations, funding sources are insurance, state quotas, offbudget revenues. 
Key partners. Key partners include a network of suppliers and partners thanks to which the business model functions. There are two types of partnerships for the health organization: 1. Strategic cooperation between complementary companies. This type includes the Federal Health System Institutions of the Russian Federation, insurance companies, public organizations, funds, research institutes and universities.

2. The manufacturer's relationship with the suppliers to ensure receiving the quality components. The Suppliers of medical equipment, pharmaceutical companies and suppliers of IT solutions for health organizations support these relations.

Customer relations. The value-based proposals are focused on the identified consumer segments and are implemented through the relationships with Customers. To implement the created value-based proposals, it is necessary to create a patient base, arrangement of the feedback system with patients through mobile applications and social media. The patients should be involved in the process for satisfaction assessment of the services provided. Thus, for example, to implement the patient rehabilitation services, specialists' on-line consultation is necessary. Early detection supposes the use of cloud services to download research results when fixing an appointment. It is also advisable to set up a system for informing the patients about the specialists' on-line timetable, the possibility for fixing an appointment (on-line, by phone, automatically in the event of preventive examination, etc.), open lectures, actions, etc.

Sales channels. Value-based proposals come to the consumer through the information networks allowing to increase the level of consumer awareness of the services to be implemented and present the value-based proposals for the potential patients. There are 2 types of sales channels for the health organization - partner and own. The partner channels include the portal of the Ministry of Health of the Russian Federation, the portals of health organizations of other regions, insurance companies. The own channel is the health organization site providing the information about the services rendered, the possibility of online fixing, as well as the information about the automatic patient fixing of an appointment with the specialists when the scheduled time for the examination is reached.

Revenue streams include the material profit that the company receives from each consumer segment. The health organization, when rendering services to individuals, earns income based on rendering the services for CHI, quotas (HTMC, HTMC as part of CHI), $\mathrm{VHI}$ or based on rendering the paid services. Receipt of income when rendering services to legal entities is carried out under the VHI.

Cost structure. Creating and implementing value-based proposals, maintaining relationships with Customers, making profits - all these processes are associated with any costs. Let's consider the most significant costs associated with functioning of the health organization business model which is implementing the Smart Hospital concept. Fixed and variable costs may generally be identified in the health organization. The feature of the health organization implementing the Smart Hospital concept is an addition of the list of fixed costs for personnel training and retraining taking into account the new requirements for personnel in the conditions of activities digitalization, medicine research and development costs and health organization activities and IT support costs including costs for activities digitization. 


\section{Conclusions}

As a result of the study, the existing medical trends and concepts that can be implemented based on the actual technologies are described. Based on the analysis of the existing approaches to creating the business models, the A. Osterwalder's model was chosen. As a result of the business model main components analysis, a description of the reference health organization business model implementing the Smart Hospital concept was developed that allows creating a specific health organization business model, forecasting its development and successful introducing the innovations. Further, it is planned to continue research in the development of the reference architectural Smart Hospital solution based on the presented reference business model.

\section{References}

1. L. Hood, Rambam Maimonides Med J 4(2) DOI: 10.5041/RMMJ.10112 (2013)

2. V. S. Baranov, Medical genetics 16(5) (2017)

3. Ye. Malyshev V. Shlyakhto, A. O. Konradi, Hyperpiesis. 8(3) (2002)

4. V. A. Stepanov. Personalized medicine: challenges and solutions [online] Available at: http://www.sbras.ru/files/files/prezidium20171221/ 5 stepanov-persmed-pressorannsk-dec2017.pdf (2017)

5. B. Jong-Myon, Epidemiol Health. 37 (2015)

6. I. V. Ilin, O. Yu. Ilyashenko, S. V. Shirokova, Levina, O. Hamalainen. Big Data for business analytics (Saint Petersburg 2016)

7. I. V. Ilin, O Yu. Ilyashynko, A.D. Borremans, Science and Education. 12(87) (2016)

8. R. Kohavi, F. Provost, Glossary of terms, 30(2-3) (1998)

9. By 2020 the Smart Hospital will be a reality [online] Available at: https://www.futurehealthindex.com/2017/06/13/by-2020-the-smart-hospital-will-be-areality/ (2017)

10. A. Osterwalder, Y. Pigneur. Business models development. 288 (Alpina Publisher Skolkovo Series, Moscow 2013)

11. D. Denisov. Open innovations model. "Business-magazine", 6. (2011) [online]Available at: http://www.cfin.ru/investor/venture/ open_innovation.shtml (2017)

12. T. Oganesyan, D. Medovnikov. The dog is still on the hay 8, 742. (2011) [online] Available at: http://expert.ru/expert/2011/08/sobaka-poka-na-sene. (2017)

13. D. Debelak, Business Models: The principles for creating a prosperous organization (Grebennikov Publishing House, Moscow 2009)

14. L. Schweizer. The concept and evolution of business models (2007) [online] Available at: http://www.research.by/webroot/delivery/files/2007n2r01.pdf. (2017)

15. Kim W. Chan, R. Moborn, Blue ocean strategy (Mann, Ivanov and Ferber, Moscow 2013).

16. Federal Law No. 323-FZ dd 21.11.2011 "Basic principles of health care of Citizens of the Russian Federation" (Article 32) [online] Available at: http://www.consultant.ru/document/cons doc_LAW 121895/. (2017)

17. Ye. Malyshev V. Shlyakhto, A. O. Konradi, O. P. Rotar, et al. Preventive medicine. 17 (5) (2014) 